\title{
ONTOLOGÍA Y EPISTEMOLOGÍA EN LA INVESTIGACIÓN CUALITATIVA
}

\author{
Alonso Aguilar V. \\ Universidad Nacional Mayor de San Marcos, Lima, Perú \\ (RECIBIDO 03/4/2012; AcEPTAdo 27/6/2012)
}

\section{INTRODUCCIÓN}

Los fundamentos teóricos metodológicos y epistémicos de la investigación cualitativa, tienen como base las tendencias que surgen con mayor fuerza durante la segunda mitad del siglo XX.

Las consideraciones en la investigación se apoyan de una serie de argumentos, que propician y favorecen la aplicación del diseño en el proceso de investigación. No obstante, los fundamentos provenientes de la ontología son cruciales en cuanto a la referencia y al método, dentro de los criterios necesarios para asumir el desarrollo en proceso cualitativo.

\section{LA ONTOLOGÍA EN LA INVESTIGACIÓN CUALITATIVA}

La ontología contemporánea tiene uno de sus puntos de partida metodológicos en la filosofía de Husserl. La idea de la fenomenología como título para una nueva actitud renovadora del pensamiento filosófico, plena de radicalidad y autenticidad en sus propósitos se halla en la base de los planteamientos contemporáneos más importantes de la ontología. La fenomenología confirió al pensamiento filosófico en general, y al ontológico en particular, una nueva perspectiva para abordar la problemática tradicional y, sobre todo, la seguridad y confianza que requerirá en una época signada por el complejo cientificista y por un sentimiento generalizado de la esterilidad del pensamiento filosófico. Esa nueva perspectiva se condensa máximamente en un anhelo vehemente por el original y genuino, en un intento por penetrar en la endurecida capa de las opiniones corrientes y mal fundadas para volver a tomar contacto con los auténticos fenómenos (Riu, 1966).

Por otro lado, el método empleado por las ciencias del espíritu se ha denominado con el viejo concepto de hermenéutica, que actualmente ha retornado al escenario. Puede decirse que la hermenéutica se ha convertido en el sentido básico del conocimiento (Bollnow, 1970). Dilthey había ya desarrollado en amplio sentido una vasta doctrina de la comprensión; abarcaba la vida humana en total, por más que él originalmente la concibiera a las ciencias del espíritu. Pero lo que en Dilthey permanecía aún en parte indeterminado, fue llevado a su comprensión por 
Heidegger, quien, como hermenéutica de la existencia humana, lo desprendió de cualquier dominio particular de objetos para trasladarlo a la vida humana en total. Heidegger muestra que ese círculo metódico que a juicio de muchos invalidaba las ciencias del espíritu tiene su fundamento necesario en la complexión de ser del hombre.

La interpretación hermenéutica y la fenomenología encuentran su locus en este apartado. Los esfuerzos en el análisis de los contenidos de los datos obtenidos en la secuencia de textos y de argumentos obtenidos en la investigación, permiten un abordaje descriptivo y legitimado de los datos, de los contenidos, orientándose entonces hacia la formación de teorías, basadas en estructuras simbólicas aproximables a una realidad determinada.

\section{LA EPISTEMOLOGÍA EN LA INVESTIGACIÓN CUALITATIVA}

El problema fundamental que ocupa a la epistemología es establecer la relación entre el ser cognoscente (sujeto) y el proceso o fenómeno sobre el cual se desarrolla su actividad cognitiva (objeto). De este modo, el problema se presenta en la relación de quien conoce y lo que es cognoscible (Guanipa, 2011).

La cuestión epistemológica, o la relación entre el sujeto que quiere conocer y aquello que ha de ser conocido, si se puede conocer el mundo real o mundo $1, y$ con qué grado de seguridad (Aliaga, nd), nos conduce a reestructurar una serie de fundamentos, posteriormente a la crisis del método.

La epistemología en la investigación cualitativa tiene un soporte proveniente de las vertientes del interaccionismo, del constructivismo y de las tendencias emancipadoras holística e integradoras, formuladas hacia la década de los setenta como el emergentismo (Hernández, Fernández y Baptista, 2006) y los enfoques sistemáticos.

Martínez (2006) señala la importancia de la inter y transdisciplinariedad exige respetar la interacción entre los objetos de estudio de las diferentes disciplinas y lograr la integración de sus aportes respectivos en un todo coherente y lógico. Esto implica, para cada disciplina, la revisión, reformulación y redefinición de sus propias estructuras lógicas individuales, ya que esas conclusiones particulares ni siquiera serían "verdad" en sentido pleno.

La dialéctica que acompaña al método y la esencia conceptual se apoya en una visión cada vez más detallada en su intento por establecer un conocimiento no especular, producto de las relaciones existentes entre el investigador y los procesos surgidos durante el desarrollo de los eventos cambiantes, la interacción y la visión del conjunto.

La ruptura epistemológica entre la metodología cualitativa y el paradigma positivista (fundamentado en el diseño cuantitativo), está precisamente en cuanto a la forma cómo se concibe el conocimiento, en la manera de adquirir ese saber, en cuanto al modo de conocer la realidad y las consideraciones en cuanto al objeto de estudio y fenómenos posibles de conocer (Ruedas, Ríos y Nieves, 2007). 


\section{TEORÍA Y METODOLOGÍA}

\section{Aspectos teóricos}

Los estudios cualitativos se fundamentan en la interpretación de las informaciones y los datos (Quecedo y Castaño, 2002). Se identifican tres componentes como configuradores del proceso de comprensión: preconcepción, comprensión actual e interpretación.

La interpretación parte de una preconcepción de lo que se pretende interpretar. La preconcepción refiere el bagaje previo del investigador, la capacidad de reconocer el hecho analizado. Este proceso permite una mayor profundidad en la comprensión al admitir dentro del marco de la investigación, interpretaciones subjetivas por parte del investigador y del investigado.

En la investigación cualitativa, se procede a analizar (observaciones, textos, episodios) con un marco teórico general. Ello conduce entonces a acudir a los contextos o textos a analizar bajo categorías previas (no categorías de análisis).

El diseño cualitativo se adapta a las teorías sustantivas, facilitándose así la recogida de datos empíricos, ofreciéndose descripciones complejas de acontecimientos y sucesos, para posteriormente desarrollar categorías y relaciones que permitan la interpretación de los datos.

La teoría actúa como un esquema previo, contextualizador y organizador del campo.

\section{Aspectos metodológicos}

El desarrollo de diseños permite a la metodología cualitativa abordar el problema de estudio desde el proceso y desarrollo de este, pero no de los resultados obtenidos. El método por excelencia es el de la teoría fundamentada (Hernández, Fernández y Baptista, 2006).

Un componente clave del método es la constante de procedimiento analítico comparativo. Este procedimiento puede ser llevado a cabo de diversas maneras, pero la idea general es que el texto se rompe en unidades de análisis (por ejemplo, una línea de texto o un párrafo o más), y de una manera u otra interpretar los significados entre las unidades que vienen a ser representados como categorías. Por lo tanto, en este escenario, son los datos que se comparan constantemente. Como el número de categorías aumenta, ellos mismos se comparan, lo que más genera categorías abstractas. Esta abstracción puede continuar hasta que un "núcleo" central o de una categoría se conceptualiza. Esta categoría organiza la teoría. Electrónico de datos basados en los programas han sido desarrollados para facilitar la gestión de los datos durante el análisis comparativo constante y para que materia común de tratamiento de texto son útiles en este sentido también.

Asimismo, para una mayor cientificidad, los criterios que comúnmente se utilizan para evaluar la calidad científica de un estudio cualitativo y por ende su rigor metodológico son la dependencia, credibilidad, auditabilidad y transferibilidad (Salgado, 2007). 


\section{CONCLUSIONES}

El desarrollo de las técnicas y diseños cualitativos se acompaña del esfuerzo logrado por asumir una postura epistemológica emergente. Sin embargo, la metodología y la teoría tienen como sede la ontología, en especial de la fenomenología, que permite asumir no solo un papel contemplativo sino producto de la interacción, vista desde un proceso más que de los resultados obtenidos.

Los sistemas emergentes y constructivistas permiten asumir un papel más complejo, interactivo y emancipador en el conocimiento, producto de una dialéctica, inmersa en los contenidos y los datos recogidos, así como de los procesos incluidos.

\section{REFERENCIAS BIBLIOGRÁFICAS}

Aliaga, F. (nd). Bases epistemológicas y procesos de investigación psicoeducativa. Documento en línea.

Bollnow, O. (1970). Introducción a la teoría del conocimiento. Buenos Aires: Amorrortu Editores.

Guanipa, M. (2011). Opciones epistemológicas y la relación dialógica en la investigación. Telos, 13 (1), 89 - 102.

Hernández, R., Fernández, C. y Baptista, P. (2006). Metodología de la Investigación. México: McGraw-Hill.

Martínez, M. (2006). La investigación cualitativa (síntesis conceptual). Revista de Investigación en Psicología, 9 (1), 123 - 146

Quecedo, R. y Castaño, C. (2002). Introducción a la metodología de la investigación cualitativa. Revista de Psicodidácticas, 14, 1-26.

Riu, F. (1966). Ontología del siglo XX. Caracas: Colección Avance.

Ruedas, M., Ríos, M. y Nieves, F. (2007). Epistemología de la investigación cualitativa. Educere, 13 (46), 627-635.

Salgado, A. (2007). Investigación cualitativa: diseños, evaluación del rigor metodológico y retos. Liberabit, $13,71-78$ 